\title{
A aventura na cidade: relações sexuais eróticas no espaço público urbano
}

Manuela Vieira Blanc*

Este artigo apresenta a discussão teórico-conceitual que permeia minha tese de doutorado em desenvolvimento e pretende relacionar o modo de vida urbano carioca e as práticas sexuais eróticas como objeto de análise. Através de uma análise do espaço urbano da cidade do Rio de Janeiro como um espaço heterogêneo em suas possibilidades de aventura e risco e do consumo de formas de lazer erótico por seus habitantes se pretende compreender os processos pelos quais segmentos da população constroem em suas vivências sociais, por intermédio de seus itinerários urbanos, suas práticas de sociabilidade relacionadas ao lazer erótico na cidade do Rio de Janeiro. Tal proposta envolve uma discussão teórica voltada para a definição da modernidade e as práticas de sociabilidade especificas de habitantes cariocas e suas interações sociais e consequentemente das formas de apropriação do espaço urbano bem como de suas relações, percepções e concepções da cidade, entendida aqui como cenário de ação desses atores. Ao mesmo tempo, a publicização de práticas íntimas no espaço urbano apresenta-se como foco de análise da experiência de vida na cidade, neste sentido, será destacada a presença de estabelecimentos de lazer erótico, como casas de strip-tease ou suingue, na cidade do Rio de Janeiro.

Palavras-chave: erótico, espaço público, aventura.

\section{Introdução}

$\square$ ste artigo apresenta a discussão $\smile$ teórico-conceitual que permeia minha tese de doutorado em andamento no Programa de Pós-Graduação em Sociologia Política da Universidade Estadual do Norte Fluminense Darcy Ribeiro - RJ. Através de uma análise do espaço urbano da cidade do Rio de Janeiro como um espaço heterogêneo em suas possibilidades de aventura e risco e do consumo de formas de lazer erótico por seus habitantes pretende-se compreender os processos pelos quais segmentos da população constroem em suas vivências sociais, por intermédio de seus itinerários urbanos, suas práticas de sociabilidade relacionadas ao lazer erótico na cidade do Rio de Janeiro. Tal proposta envolve

\footnotetext{
${ }^{*}$ Mestre em Ciências Sociais PPCIS/UERJ, atualmente doutoranda em Sociologia Política PPGSP/ UENF. E-mail: manu_uenf@yahoo.com.br
} 
This paper presents the theoretical and conceptual discussions that permeates my doctoral thesis on development and intends to link the urban way of life in Rio and erotic practices as object of analysis. Through an analysis of urban space in Rio de Janeiro as a heterogeneous space in their possibilities of adventure and risk and consumption of forms of erotic pleasure for its people I want to understand the processes by which segments of the population build social experiences through their urban itineraries, its practices of sociability related to erotic entertainment in Rio de Janeiro. This proposal involves a theoretical discussion focused on the definition of modernity and the specific practices of sociability inhabitants cariocas and their social interactions and consequently the forms of appropriation of urban space and their relationships, perceptions and conceptions of the city, understood here as a backdrop of action of these actors. At the same time, the publicizing of intimate practices in urban space presents itself as the focus of analysis of the experience of city life, this sense will be highlighted the presence of erotic entertainment establishments such as Streep-tease or swing clubs in the city Rio de Janeiro.

Key words: Erotic, public space, adventure.

uma discussão teórica voltada para a definição da modernidade e as práticas de sociabilidade especificas de habitantes cariocas e suas interações sociais e consequentemente das formas de apropriação do espaço urbano bem como de suas relações, percepções e concepções da cidade, entendida aqui como cenário de ação desses atores.

Tomados como campo de análise alguns estabelecimentos de lazer erótico, a relação entre consumo e construção de si apresenta-se como questão fundamental a ser confrontada em suas diferentes percepções teórico-metodológicas como ferramenta para se pensar o próprio objeto de análise.

O advento de formas modernas de relacionar-se é acompanhado por um movimento igualmente amplo de transformações não apenas das formas legitimadas de exercício da sexualidade, como também da redefinição das fronteiras entre espaço público e privado, sejam tipicamente caracterizadas como ilegítimas às práticas sexuais (enquanto dimensão estritamente íntima) por um lado ou receptáculo de segredos impudicos por si mesmo, por outro, respectivamente. ${ }^{1}$

O contexto urbano moderno, ao mesmo tempo em que leva esta oposição fundamental entre espaços de sociabilidade e ação ao seu mais alto grau, ao lançar o espaço público como local legítimo ao exercício da vida pública, caracte-

\footnotetext{
${ }^{1}$ COMBESSIE, Philippe. Le partage de l'imtimite sexuelle. Pistes pour une analyse du pluripartenariat au feminin. In: LE GALL, Didier. Identités et genres de vie. Chroniques d'une autre France (2008) Paris: L'Harmattan, 2008.
} 
riza-se por uma superação de tal polarização que reflete e potencializa sensíveis transformações na construção social dos sujeitos, bem como de suas relações sociais $^{2}$, favorecendo o desenvolvimento e coexistência de uma pluralidade de formas de sociação, bem como de identidades sociais.

Nas grandes metrópoles modernas a impessoalização das relações, concomitantemente ao advento da própria noção de indivíduo, propicia e é também potencializada pelo estabelecimento de relações públicas permeadas por conteúdos de foro privado. A publicização de práticas sexuais, bem como a constituição de relações sexuais destacadas de um caráter afetivo ou duradouro para ambos os sexos é apontada por muitos autores como fenômeno integrante a própria modernidade e, neste movimento, a própria ética moral assume novo significado, variante e referenciado com relação ao que é apontada como uma moral tradicional. ${ }^{3}$

No Brasil, entretanto, é necessário levar-se em consideração características específicas presentes na relação entre espaço público e privado, assumida como uma oposição inerente e complementar, fundadora da própria organização social. ${ }^{4}$

Neste trabalho, atenho-me à discussão teórico-conceitual a partir da qual será desenvolvido um estudo empírico em estabelecimentos de lazer erótico na cidade do Rio de Janeiro.

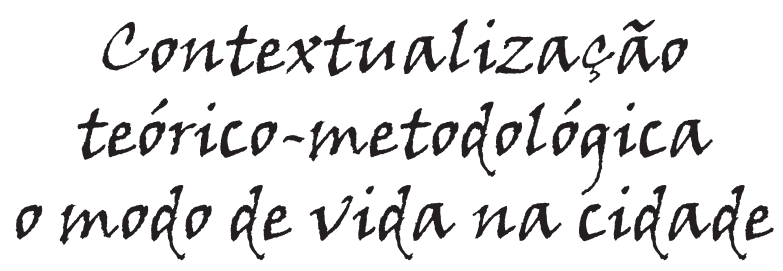

A cidade é apreendida enquanto espaço de vivências que se caracteriza pela pluralidade e pela transitoriedade. Stanley Parker defende tratar-se o contexto urbano ao mesmo tempo de um reflexo e um condicionante de formas específicas de re-

\footnotetext{
${ }^{2}$ ARENDT, Hanna. A condição humana. $10^{\circ}$ ed. Rio de Janeiro: Forense Universitária, 2000.

${ }^{3}$ Entre outros, SIMMEL, George. A filosofia do amor. São Paulo: Martins Fontes, 1993; GIDDENS, Anthony. A transformação da intimidade: sexualidade, amor \& erotismo nas sociedades modernas. São Paulo: Editora da Universidade Estadual Paulista, 1993.
}

${ }^{4}$ DA MATTA, Roberto. A casa e a rua. $5^{\circ}$ edição. Rio de Janeiro: Rocco, 1997. 
lacionar-se caracterizadas, acima de tudo, por uma multiplicidade altamente rica em termos de formas e de significados, já que no contexto urbano tais arcabouços valorativos se configuram apenas como ponto a partir do qual serão redefinidos, em proporções e velocidade maiores do que em qualquer outro meio social. ${ }^{5}$ Neste sentido, a cidade é apontada por diversos autores como o lugar do efêmero, da construção destrutiva. ${ }^{6}$ Simulacro de mapas afetivos de pertencimento territoriais dos sujeitos desenhados por dinâmicas coletivas ${ }^{7}$, espaço caracterizado pela alta densidade populacional e pela coexistência de grupos sociais diversificados, tanto social quanto economicamente, a cidade contemporaneamente apresenta-se como elemento fundamental para a própria caracterização/análise da modernidade. Segundo Louis Wirth, o desenvolvimento e crescimento das cidades enquanto forma de vida preponderante na atualidade caracteriza "o início do que pode ser considerado marcantemente moderno em nossa civilização". ${ }^{8}$

O espaço urbano é destacado por Ana Luiza Rocha e Cornélia Eckert pela multiplicidade de possibilidades de experimentação e espontaneidade que coloca à disposição de seus habitantes ${ }^{9}$, ao que Zygmunt Bauman irá se opor através de seu argumento em torno da conceituação da realidade urbana contemporânea como uma forma líquida de vida. Segundo Bauman, a

'vida líquida' e a 'modernidade líquida' estão intimamente ligadas. A 'vida líquida' é uma forma de vida que tende a ser levada à frente numa sociedade líquido-moderna. 'Líquidomoderna' é uma sociedade em que as condições sob as quais agem seus membros mudam num tempo mais curto do que aquele necessário para a consolidação, em hábitos e rotinas, das formas de agir. ${ }^{10}$

Bauman caracteriza tal contexto por uma multiplicidade de direcionamentos e valores mutantes em si mesmos, que carecem de uma linearidade e, ao mesmo tempo, de uma constância. A vida líquida é assim caracterizada por uma

${ }^{5}$ PARKER, Stanley. A sociologia do lazer. Rio de Janeiro: Zahar Editores, 1978.

${ }^{6}$ BAUMAN, Zygmunt. Confiança e medo na cidade. Rio de Janeiro: Zahar Editores, 2009.

${ }^{7}$ ROCHA, Ana Luiza Carvalho da e ECKERT, Cornélia. O tempo e a cidade. Porto Alegre: Editora da UFRGS, 2005.

${ }^{8}$ WIRTH, Louis. O urbanismo como modo de vida. In: VELHO, Otávio Guilherme. O fenômeno urbano. $4^{\mathrm{a}}$ edição. Rio de Janeiro: Zahar Editores, 1979, p. 90.

${ }^{9}$ ROCHA, Ana Luiza Carvalho da e ECKERT, Cornélia. Op. cit.

${ }^{10}$ BAUMAN, Zygmunt. Vida liquida. Rio de Janeiro: Zahar Editores, 2007, p. 7. 
vida precária, demarcada por uma necessidade incessante de recomeçar, já que não há caminhos pré-definidos a serem seguidos. Mais do que a experimentação, esta forma de vida é caracterizada pela destruição criativa, segundo ele. Dada tal realidade, o espaço urbano estaria fadado a perder seu potencial integrador da diversidade.

Tal apreensão é a base da análise de Georg Simmel quanto à vida mental na metrópole, em que o autor destaca consequências objetivas para a compreensão subjetiva da realidade no contexto urbano ${ }^{11}$. Segundo o autor, a base psicológica do homem metropolitano é caracterizada por uma intensificação dos estímulos nervosos, resultando na alteração brusca e ininterrupta entre estímulos exteriores e interiores. O cotidiano citadino implica para seus habitantes uma consciência, ou "quantidade" de consciência, diferente da que a vida rural extrai: uma intelectualidade elevada e, por consequência, indiferente a toda individualidade genuína, segundo o argumento do autor. Em termos práticos e como forma de autopreservação, a atitude blasé surge como uma incapacidade de reagir a novas sensações. As múltiplas possibilidades de experimentação da realidade, a heterogeneidade que a caracteriza, culminam num isolamento subjetivo do sujeito urbano.

Georg Simmel desenvolve o conceito de aventura, importante auxiliar para tratar a relação entre oferta e procura de diversas formas de sociabilidade e lazer na cidade. Mais do que a simples noção de experimentação, o autor analisa a aventura como evento que "extrapola o contexto da vida. [...] uma parte da nossa existência à qual - pela frente e por trás se ligam imediatamente outras, mas que, ao mesmo tempo, em seu sentido profundo, corre por fora de qualquer continuidade desta vida"12. Vivências que se destacam da normatividade tanto em aspectos objetivos quanto subjetivos, dotados de uma lógica própria e plena, cujo início, meio e fim independem da, contradizendo ou até mesmo opondo-se a, realidade exterior. Através deste conceito é possível pensar o modo de vida urbano, e a oferta de "serviços" que se caracterizam por uma lógica que se choca com os valores morais socialmente legitimados, como fenômeno paralelo às experiências dos sujeitos urbanos modernos, destacados do cotidiano da vida.

\footnotetext{
${ }^{11}$ SIMMEL, George. A metrópole e a vida mental. In: VELHO, Otávio Guilherme. O Fenômeno Urbano. $4^{\mathrm{a}}$ edição. Rio de Janeiro: Zahar Editores, 1979.

${ }^{12}$ SIMMEL, George. A aventura. In: SOUZA, Jessé e ÖELZE, Berthold. Simmel e a modernidade. Brasília: UnB. 1998, p. 171.
} 
A aventura se constitui como uma parte da existência entrelaçada na interrupção desta, mas que, todavia, pode ser sentida como uma totalidade, uma unidade acabada. É o "jardim secreto" da própria existência humana que constitui em si uma configuração de sentido fixada por meio de um começo e um fim e que está, apesar de "toda a sua causalidade e toda sua exterioridade perante o fluxo contínuo da vida, em conexão com a essência e com a determinação do sujeito em um sentido amplo - que se alastra aos segmentos racionais da vida - e em uma necessidade secreta". ${ }^{13}$

Entendida como espaço potencial de "aventura" e "risco", a cidade do Rio de Janeiro é apreendida como celeiro de modos de vida e sociabilidade múltiplos. Identificados estabelecimentos de lazer eróticos em diversos pontos da cidade, objetivo compreender até que ponto estes espaços encerram específicas formas de sociabilidade e construção de si. Ao mesmo tempo, tais serviços apontam para um processo de publicização de práticas de foro íntimo, assim como peculiares usos do espaço público.

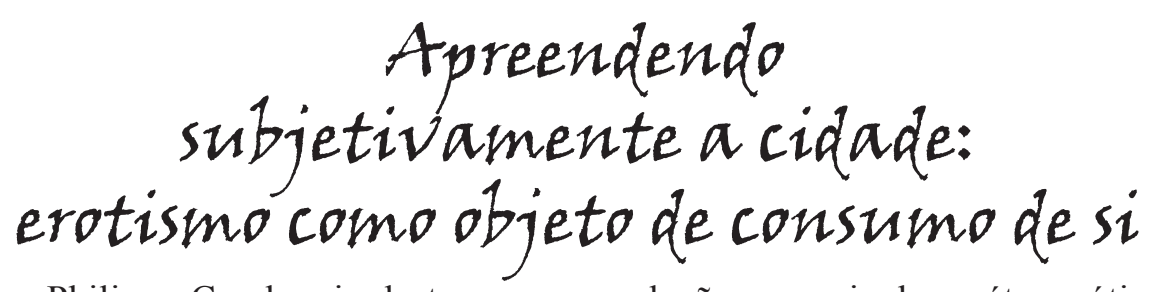

Philippe Combessie destaca que as relações sexuais de caráter erótico ${ }^{14}$ devem ser analisadas através de três aspectos da sociedade, e que interferem em condições de reconhecimento, de facilitação ou de limitação a tais práticas: o desenvolvimento do individualismo, dos meios de comunicação e das trocas comerciais aqui destacadas como a publicização de práticas de foro íntimo e a relação entre o modo de vida urbano e as possibilidades de consumo que propicia. O erótico é aqui apreendido como um conjunto de representações

\footnotetext{
${ }^{13}$ SIMMEL, George. A aventura. Op. cit., p. 174.

${ }^{14}$ COMBESSIE, Philippe. Le pluripartenariat sexuel: une communauté interstitielle? In: SAINSAULIEU, I; SALZBRUNN, M.; AMIOTTE-SUCHET, L. (Ed.) Faire communauté en société. Dynamiques des appartenances collectives. Rennes : Presses Universitaires de Rennes, 2010. Destaco que, assim como será apresentado, o autor analisa especificamente práticas comunais de pluriparceria sexual, sob o foco das experiências femininas.
} 
quanto à sexualidade que difere dos planos afetivos, reprodutivos ou conjugais ao caracterizar-se pela experiência do prazer, a satisfação de desejos sexuais individuais, seja através da realização/intenção do ato sexual em si ou práticas que remetem à busca por sua satisfação, mesmo que em caráter exclusivamente lúdico. ${ }^{15}$

Analisando as práticas sexuais femininas de pluriparceria (do original pluripaternariat), ou seja, o exercício de relações sexuais com múltiplos parceiros, seja em relações efêmeras, o exercício de práticas sexuais coletivas ou o estabelecimento de práticas sexuais paralelas com dois ou mais parceiros (havendo ciência e consentimento das partes ou não), o autor diferencia tal exercício da sexualidade de contatos sexuais permeados por laços sentimentais caracterizados por uma dependência mútua que se estende espaçotemporalmente e na qual a dinâmica de "dom" e "contra-dom" maussiana atravessa as trocas sexuais e a engloba a partir de uma lógica totalizante. Philippe Combessie se propõe a analisar tais comportamentos como práticas sociais propriamente ditas, permeadas pela construção de sentidos auto-referidos e que estão inseridas em específicas trajetórias, dotadas de dimensões tanto coletivas quanto pessoais. Ao mesmo tempo, analisa o contexto social em que se inserem como um corpus de sociabilidade e construção de sentido de dinâmica específica. ${ }^{16}$

A partir de Durkheim, o autor chama atenção para o fato de que o ato sexual aciona sentidos contrários à própria consciência moral, as emoções por ele destacadas assumem a forma de injunções e contradições que, no que se refere à sociedade contemporânea, conduz a uma oposição caricatural, envolvendo, de um lado, a figura materna assexuada e, de outro, a figura da puta. Ao mesmo tempo, os "saberes" práticos desenvolvidos gradualmente, à medida do progresso de uma vida sexual de pluriparceria, permite às mulheres acumular vantagens a partir da conjugação de ambas as figuras. A libertação de seus corpos através da desconexão entre sexualidade e relações diádicas exclusivas, privilégio atribuído à puta; e a conservação da respeitabilidade da figura materna. ${ }^{17}$

\footnotetext{
${ }^{15}$ DUARTE, Luiz Fernando Dias et all (Orgs.). Sexualidade, Família e Ethos Religioso. São Paulo: Editora Garamond, 2005

${ }^{16}$ COMBESSIE, Philippe. Le partage..., Op. cit.

${ }^{17}$ COMBESSIE, Philippe. Le pluripartenariat... Op. cit. p 9.
} 
Le pluripartenariat sexuel qui établit des liens tellement puissants entre les individus et groupes du communisme sexuel analysé par Mauss chez les Inuits ne peut pas, dans la société occidentale contemporaine qui érige en valeur sacrée la relation d'amour dyadique exclusive, être légitimé autrement que dans le cadre de communautés interstitielles, qui se développent dans les marges de la société. ${ }^{18}$

O autor identifica e analisa essas comunidades intersticiais capazes de dotar tais práticas de um sentido que lhe é próprio, conciliando o paradoxo entre estas e a moralidade sexual socialmente legitimada e conferindo coerência às narrativas sexuais. Ao mesmo tempo estas se constituem como ilhas valorativas, desenvolvidas à margem da moralidade dominante, sendo circunscritas em espaços bem delimitados e através de regras e valores éticos específicos a cada micro-grupo. ${ }^{19}$

A cultura moderna é caracterizada pela preponderância do que se poderia chamar de o "espírito objetivo" sobre o "espírito subjetivo"20; como forma de afirmação de uma personalidade individual, os sujeitos se voltam para diferenças qualitativas, traduzindo em "extravagâncias" um projeto de diferenciação e notabilidade. As relações são restringidas a uma lógica comercial, impessoal e progressivamente mais calculista: "essa necessidade é criada pela agregação de tantas pessoas com interesses tão diferenciados, que devem integrar suas relações e atividades em um organismo altamente complexo". ${ }^{21}$

Seguindo o mesmo caminho, Zygmunt Bauman destaca que a "vida líquida", carente de fontes objetivas ou subjetivas de sentido, é uma vida de consumo. Esta projeta o mundo e "todos os seus fragmentos animados e inanimados como objetos de consumo, ou seja, objetos que perdem a utilidade (e portanto o viço, a atração, o poder de sedução e o valor) enquanto são usados"22. Bauman integra desta forma a longa lista de autores que relacionam modernidade e consumo

\footnotetext{
${ }^{18}$ A pluriparceria sexual que estabelece ligações tão poderosas entre os indivíduos e grupos do comunismo sexual analisado por Marcel Maus entre os Inuit não pode, na sociedade ocidental contemporânea, na qual se erige em valor sagrado a relação de amor diádico exclusivo, ser legitimado senão no quadro das comunidades intersticiais, que se desenvolvem as margens da sociedade (tradução livre). COMBESSIE, Philippe. Le pluripartenariat... Op. cit. p 12.

${ }^{19}$ COMBESSIE, Philippe. Le pluripartenariat... Op. cit..

${ }^{20}$ SIMMEL, George. A metrópole... Op. cit., p. 23.

${ }^{21}$ Idem, p. 15.

${ }^{22}$ BAUMAN, Zygmunt. Vida.... Op. cit., p. 16.
} 
como elementos fundamentais para se pensar as relações sociais na contemporaneidade e, em certos casos, até mesmo a noção moderna de indivíduo. A construção dos sujeitos como mercadorias é apontada como consequência de uma busca por satisfação retroalimentada por uma total incapacidade de satisfazer-se. A partir do estabelecimento de um objeto típico ideal, no sentido weberiano, Bauman caracteriza o ‘consumismo’ como um

tipo de arranjo social resultante da reciclagem de vontades, desejos e anseios humanos rotineiros, permanentes e, por assim dizer, 'neutros quanto ao regime', transformando-os na principal força propulsora e operativa da sociedade, uma força que coordena a reprodução sistêmica, a integração e a estratificação sociais, além da formação de indivíduos humanos, desempenhando ao mesmo tempo um papel importante nos processos de auto-identificação individual e de grupo, assim como na seleção e execução de políticas de vida individuais. $\mathrm{O}$ 'consumismo' chega quando o consumo assume o papel-chave que na sociedade de produtores era exercido pelo trabalho. ${ }^{23}$

Parafraseando Latour e em consonância com a análise simmeliana, Bauman destaca que a 'subjetividade' numa sociedade de consumidores, assim como a 'mercadoria' numa sociedade de produtores, é um fetiche. Fetiche no sentido de um produto eminentemente humano ao qual é conferida a categoria de autoridade sobre-humana. Dada a ausência de fontes totalizadoras de sentido, sejam elas dadas pelo Estado, a religião ou a própria vida comunitária, os indivíduos passam a "consumir" formas de ser e se mostrar como fonte de satisfação pessoal e construção identitária. Ao mesmo tempo, a vida para consumo, produto do contexto moderno e urbano, é caracterizada por uma luta por satisfação movida pelo seu constante adiamento, que se transfere ao mesmo tempo para o domínio das relações pessoais. ${ }^{24}$

Apesar das especificidades de suas perspectivas, as análises de Simmel e Bauman se aproximam desta forma do conceito de relação pura construído por Anthony Giddens, exemplificado por uma transferência para o domínio dos vínculos humanos de regras típicas do mercado de bens. ${ }^{25}$ Vida íntima e engaja-

\footnotetext{
${ }^{23}$ BAUMAN, Zygmunt. Vida para Consumo: A transformação das pessoas em mercadoria. Rio de Janeiro: Jorge Zahar Editores, 2008, p. 41.

${ }^{24}$ Idem .

${ }^{25}$ GIDDENS, Anthony. Op. cit.
} 
mento social demarcadas pela instabilidade, a dificuldade de estabelecimento de uma trajetória coerente para o eu e a busca por satisfação no estabelecimento de relações com "objetos" humanos e não-humanos que é sempre incompleta por natureza.

Anthony Giddens caracteriza a relação pura como tipo de envolvimento amoroso baseado única e exclusivamente no interesse de ambas as partes em encontrar plena satisfação através do estabelecimento da relação. ${ }^{26}$ Tal conceito em muito se aproxima da noção de erótica desenvolvida por George Simmel. ${ }^{27}$ Ao contrário do ethos do amor romântico, onde a absorção de um pelo outro se apresenta como aspecto central do estabelecimento da relação, o relacionamento puro refere-se

Assim como no mercado de bens, marcado pela instabilidade e a constante busca a uma situação em que se entra em uma relação social apenas pela própria relação, pelo que pode ser derivado por cada pessoa da manutenção de uma associação com outra, e que só continua enquanto ambas as partes considerarem que extraem dela satisfações suficientes, para cada uma individualmente, para nela permanecerem. ${ }^{28}$

por uma satisfação utópica por natureza, porque pautada numa expectativa crescente pela construção de si mesmo através da absorção do outro (ou de outra coisa), "o amor confluente é um amor ativo, contingente, e por isso entra em choque com as categorias 'para sempre' e 'único'da idéia do amor romântico". ${ }^{29}$ Ao mesmo tempo, o amor confluente, forma de relacionamento puro, se desenvolve como um ideal de uma sociedade marcada pela oportunidade conferida a todos os seus membros de se tornarem sexualmente realizados e pela superação da dicotomia entre mulheres "respeitáveis" e àquelas marginalizadas da vida social ortodoxa.

Zygmunt Bauman e Anthony Giddens apresentam um contexto extremamente conflituoso para a constituição de relações sociais, onde o conflito, segundo o conceito simmeliano, está sempre renegado a uma não relação, dada a

\footnotetext{
${ }^{26}$ Idem.

${ }^{27}$ SIMMEL, George. A filosofia.... Op. cit.

${ }^{28}$ GIDDENS, Anthony. Op.cit, p. 68.

${ }^{29}$ Idem, p. 72 .
} 
ausência de forças em favor da sua unificação. O conflito simmeliano caracteriza-se por uma forma de associação composta simultaneamente por harmonia e discórdia, e é um elemento inerente a toda associação. ${ }^{30}$ As análises de Bauman e Giddens apontam para uma realidade social marcada por uma espécie de não engajamento, ou incapacidade de integrar um todo que, por sua heterogeneidade de sentidos, bem como pela instabilidade destes, carece de uma capacidade de mostrar-se como fonte de segurança ontológica ${ }^{31}$, seguindo as conclusões do próprio Simmel com relação à vida na cidade moderna. ${ }^{32}$

Apreendida superficialmente como uma construção baseada numa visão compartimentada entre tempo útil (ou de trabalho) e tempo ocioso, um momentum de livre direcionamento, de experimentação informalizada do outro, do espaço e da própria cultura urbana, considerada em suas múltiplas e flexíveis faces, o lazer em sua expressão contemporânea seria fruto da moderna concepção de trabalho. O lazer é uma instituição social, destaca Stanley Parker ${ }^{33}$, elemento inerente a concepção moderna de indivíduo e de direitos individuais (sobretudo relacionados à regulação do trabalho) e, como tal, se insere numa lógica mais ampla, analisada por Bauman a partir da lógica de consumo. ${ }^{34} \mathrm{La}-$ zer, indivíduo, consumo e cidade como elementos auto-referentes no contexto capitalista.

Ao mesmo tempo o contexto da modernidade assim marcado por uma busca por reconhecimento através da construção de si como sujeito único e diferenciado, seja na demarcação de identidades sociais ou no estabelecimento de práticas que extravasam comportamentos socialmente legitimados como medianos, assim como demanda sujeitos capazes de ausentar-se de quaisquer elementos que lhes possam identificar diretamente com tal ou qual ideologia ou modo de vida, denota amplas questões no que se refere ao estabelecimento de vínculos sociais. A transformação dos indivíduos em mercadoria, ao mesmo tempo que em con-

\footnotetext{
${ }^{30}$ SIMMEL, George. O conflito. In: MORAES FILHO, Evaristo de (Org.). Sociologia. São Paulo: Ática, 1983.

${ }^{31}$ Ver GIDDENS, Anthony. Novas Regras do Método Sociológico. $2^{\mathrm{a}}$ ed. Lisboa: Gradiva Publicações, 1996.

${ }^{32}$ SIMMEL, George. A metrópole... Op. cit.

${ }^{33}$ PARKER, Stanley. Op. cit..

${ }^{34}$ BAUMAN, Zygmunt. Vida líquida... Op. cit.
} 
sumidores potencialmente ativos, cria um paradoxo subjetivo aos seus membros em relação já que "o destino final de toda a mercadoria colocada à venda é de ser consumida por compradores". Ao mesmo tempo, "os compradores desejarão obter mercadorias para consumo se, e apenas se, consumi-las for algo que prometa satisfazer seus desejos". E não podemos nos esquecer de que "o preço que o potencial consumidor em busca de satisfação está preparado para pagar pelas mercadorias em oferta dependerá da credibilidade dessa promessa e da intensidade desses desejos". ${ }^{35}$

Ao mesmo tempo a noção de erótico definida por Simmel difere do amor no que se refere à perspectiva através da qual parte. Enquanto o amor caracterizase por uma busca de si através da busca do outro, onde a individualidade do ser amado é o argumento mesmo para a legitimidade de tal sentimento, para a

natureza erótica, a relação afetiva unicamente possível em relação a um indivíduo (e, para dizer a verdade, inclusive em relação a um só indivíduo) torna-se uma relação geral permanente (se bem que em diversos graus), mas sem cair na renegação panteísta da individualidade. ${ }^{36}$

A busca pela satisfação de tal apelo erótico, mesmo ao assentar-se sobre um sujeito determinado, faz-se através do impulso geral pela satisfação mesma, fugindo a uma identificação direta com o objeto de desejo senão como ferramenta capaz de conceder a tão procurada sensação de prazer. Neste sentido, o autor destaca que "a importância do prazer se estende a momentos tanto mais afastados, alusivos, simbólicos, do domínio erótico, quanto mais refinada e culta for a personalidade". ${ }^{37}$

O amor - na natureza erótica - é uma auto-relação, fechada em si mesma. A natureza erótica existe mesmo quando não existe alguém para amar. $\mathrm{O}$ amor é um ser do sujeito, ligado a determinado objeto ou com a vida apenas de forma secundária. ${ }^{38}$

No contexto moderno, portanto, as relações eróticas assumem um grau ainda mais elevado no que se refere tanto à multiplicidade de fontes (sejam elas

\footnotetext{
${ }^{35}$ BAUMAN, Zygmunt. Vida para Consumo... Op. cit., p. 18

${ }^{36}$ SIMMEL, George. A filosofia.... Op. cit., p. 179.

${ }^{37}$ Idem, p. 99.

${ }^{38}$ Idem., p. 101.
} 
simbólicas ou práticas) de seu exercício quanto ao caráter impessoal e fugidio do encontro entre corpos, mesmo que em um sentido metafórico, e a vivência de aventuras.

Deve-se destacar a ligação entre o conceito de aventura simmeliano, sua forma erótica e a própria teoria freudiana da repressão sexual: "Segundo Freud, é a transformação do princípio de prazer em princípio de realidade" ${ }^{39}$, que caracteriza a formação do sujeito através da transformação de seu sistema instintivo. O aventurar-se se situa, neste sentido, como um ponto de fuga, dotado de contradições e percepções específicas.

A identificação de um processo de objetivação dos atos íntimos não pressupõe um esvaziamento subjetivo dos conteúdos sexuais eróticos. Michel Bozon destaca que nada de sexual pode haver sem que haja produções sociais e mentais, cenários subjetivos nos quais atos, relações e significados da sexualidade se encontrem inscritos e organizados. Ao mesmo tempo, esses cenários estruturados são também estruturantes, intervindo na produção do desejo sexual e, na sociedade contemporânea, também na construção de si. A hipótese inovadora repousa sobre a existência de configurações distintas, mesmo que em número limitado, que associem práticas sexuais e representações de si, "de modo que tal associação contribua de maneiras bem distintas para a construção dos individuos". ${ }^{40}$

O que se pretende analisar é a relação entre um exercício publicizado do erotismo por homens e mulheres, em diferentes níveis de aproximação objetiva/ subjetiva (ou seja, desde o observar de corpos sedutores em shows de streep-tease até o exercício público do ato sexual em casas de swingue), e relacionar tais práticas com o contexto mais amplo de estabelecimento de relações sociais e construção de si enquanto parte da sociedade como um todo, no contexto urbano brasileiro, através da experiência de aventura. A busca por estabelecimentos de lazer erótico inseridas no contexto urbano moderno de delimitação de identidades e relações sociais como ferramenta de apreensão da construção da noção de indivíduo na sociedade moderno-brasileira.

\footnotetext{
${ }^{39}$ CROCCO, Fábio Luiz Tezini. Estudo crítico sobre a transformação da ideologia e da subjetividade. www.psicanaliseefilosofia.com.br/.../Vol2.../estudo\%20critico.pdf, p. 48.

${ }^{40}$ BOZON, Michel. Sociologia da sexualidade. Rio de Janeiro: Editora FGV, 2004, p. 134.
} 


\section{Considerações finais}

Este artigo se restringe às questões teórico-conceituais tomadas como base para o desenvolvimento de minha tese de doutoramento, que deverá ser defendida no primeiro semestre de 2013 pelo PPGSP/UENF. Atualmente está sendo realizado o trabalho de campo em alguns estabelecimentos de lazer erótico da cidade do Rio de Janeiro.

Inicialmente serão descartadas ofertas de serviços sexuais propriamente ditos, caracterizadas pela prostituição sexual, entendendo que o desenvolvimento de trocas monetárias no estabelecimento de relações sexuais introduz questões específicas. Primeiro por conotar uma percepção peculiarmente negativizada pela sociedade ocidental contemporânea, ao mesmo tempo apresentando-se nesses casos como o exercício de um comportamento destacado de comunidades intersticiais fundadas a partir de grupos de sociabilidade autoreferenciados e dotados de ume ética própria capaz de tornar coerentes as narrativas individuais, mesmo que a partir de uma existência marginal. Ao mesmo tempo tais práticas fogem ao propósito de compreensão das práticas sexuais de cunho erótico aqui destacadas, por se apresentarem como uma ruptura com o intercâmbio sexual propriamente dito, perturbando a dinâmica de tipo dom/contra-dom segundo a qual a reciprocidade é uma condição para o desenvolvimento da própria comunidade, assim como salienta Philippe Combessie. ${ }^{41}$

Considera-se a possibilidade de que profissionais do Streep-tease possam oferecer tais serviços, assim como que o consumo sexual seja relacionado com relativa freqüência às práticas de sexo grupal em casas de swingue, mas, no primeiro caso o enfoque está sobre os freqüentadores de casas de show que, ao menos oficialmente, não oferecem serviços de prostituição ${ }^{42} \mathrm{e}$, no segundo, tais práticas estão relacionadas a um contexto relacional mais amplo, que tende a extrapolar a relação comercial diádica. O foco, portanto, recai muito mais sobre esses espaços de sociabilidade erótica como oferta

\footnotetext{
${ }^{41}$ COMBESSIE, Philippe. Le pluripartenariat.... Op.cit, p. 7.

${ }^{42} \mathrm{E}$ mesmo a oferta informal de tais serviços nestes espaços parece ser pouco comum, ao menos entre os gogo boys analisados por ARENT, Marion; CARRARA, Sergio. Gênero, sexualidade, corpo e trabalho: Etnografia em um Clube das Mulheres. Revista PSICO, v. 38, n 3, pp. 254-261, set./dez., 2007.
} 
de serviço e publicização da intimidade do que sobre o "consumo sexual" propriamente dito.

Uma das hipóteses norteadoras da pesquisa corresponde a uma apreensão das práticas sexuais de cunho erótico como fenômeno de publicização de questões de foro íntimo, apontada por muitos autores como característica da modernidade. ${ }^{43}$ Outra se refere a um processo de autonomização do campo das práticas de lazer erótico através da constituição de um mercado específico, bem como da legitimação desses modos de vida através do estabelecimento de comunidades intersticiais, assim como a definição estabelecida por Philippe Combessie.

A metodologia utilizada deverá se basear no método da teoria fundamentada. Mais do que o estabelecimento de uma descrição densa da realidade, capaz de captar os significados dos comportamentos observados, ${ }^{44}$ objetivo construir a partir da coleta de dados uma análise pautada na densidade conceitual propriamente dita, ou seja, o rico conhecimento de conceitos e relações "que se mantêm em grande familiaridade com os dados associados e são com eles sistematicamente confrontados". ${ }^{45}$ Para tanto serão utilizadas como ferramentas de coleta de dados a observação etnográfica nos estabelecimentos de lazer eróticos previamente selecionados e a realização de entrevistas semi-estruturadas com seus usuários. Eventualmente alguns dos atores responsáveis pela oferta de tais serviços poderão também ser entrevistados: funcionários de forma geral e, sobretudo, streepers. Enquanto sujeitos posicionados, suas representações da realidade vivenciada serão consideradas como dados significativos para a compreensão do seu posicionamento. Ao mesmo tempo, parto do pressuposto de que os pesquisadores "assumem a responsabilidade ulterior de interpretar o que é observado, visto ou lido" em termos do estabelecimento de uma análise social. ${ }^{46}$

\footnotetext{
${ }^{43}$ Ver, entre outros, SIMMEL, George. A filosofia do amor... Op. cit.; GIDDENS, Anthony. A transformação.... Op. cit.

${ }^{44}$ GEERTZ, Clifford. Uma descrição densa: por uma teoria interpretativa da cultura. In: Interpretação das Culturas. Rio de Janeiro: Zahar, 1978.

${ }^{45}$ STRAUSS, Anselm e CORBIN, Juliet. Metodologia da Teoria Fundamentada: uma visão geral. In: www.orbispictus.com.br/downloads/MTF.pdf, p. 2, acessado em outubro de 2009

${ }^{46}$ Idem, p. 2.
} 